\title{
Petrous Apex Meningioma with Extension into Meckel's Cave: Resection using a Retrosigmoid Intradural Suprameatal Approach
}

\author{
Stephan A. Munich ${ }^{1}$ Jacques J. Morcos ${ }^{1}$ \\ ${ }^{1}$ Department of Neurosurgery, University of Miami, Miami, \\ Florida, United States
}

J Neurol Surg B 2019;80(suppl S3):S300-\$301. Address for correspondence Stephan A. Munich, MD, Department of
Neurosurgery, University of Miami, 1095 Northwest, 14th Terrace, Miami,
FL 33136, United States (e-mail: Stephan.Munich@gmail.com).

\begin{abstract}
Keywords

- meningioma

- petrous apex

- retrosigmoid

- retrosigmoid intradural suprameatal approach

The retrosigmoid intradural suprameatal approach was first introduced in 1983 by Samii et al, as a modification of the classic retrosigmoid approach intended to open Meckel's cave, exposing the trigeminal nerve and access the middle fossa. ${ }^{1}$ The area of bone resected in this approach is similar to that removed in a Kawase's approach. ${ }^{2}$ Whereas the direction of drilling in a Kawase's approach is from anterior and superior, it is from posterior and inferior in the retrosigmoid intradural suprameatal approach. Seoane and Rhoton quantified the exposure of Meckel's cave, finding that this approach allowed access, on average, to the posterior $10.3 \mathrm{~mm}$ of Meckel's cave. ${ }^{3}$ This was confirmed by Chanda and Nanda who found that suprameatal drilling resulted in a mean gain of exposure of the trigeminal nerve of $10.7 \mathrm{~mm} .{ }^{4}$ In this video, we present the case of a patient when an enlarging petrous apex meningioma with extension into Meckel's cave (-Fig. 1). The patient underwent a retrosigmoid intradural suprameatal approach to achieve a Simpson's grade II resection. This approach was ideally suited for this case to obtain access to tumor located at the petrous apex and within Meckel's cave (-Fig. 2). Without access to Meckel's cave provided in this approach a significant portion of tumor would have remained in situ. The link to the video can be found at: https://youtu.be/eNldkF4a_OI.
\end{abstract}

Conflict of Interest

None.

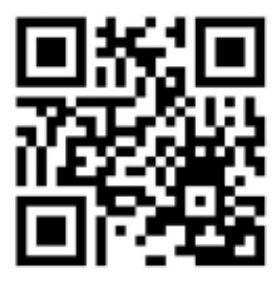

received

May 29, 2018

accepted

November 11, 2018

published online

January 4, 2019 www.thieme.com/skullbasevideos

www.thieme.com/jnlsbvideos

DOI https://doi.org/

10.1055/s-0038-1676996. ISSN 2193-6331. (c) 2019 Georg Thieme Verlag KG
Stuttgart · New York

License terms

(c) $\odot \ominus$ 


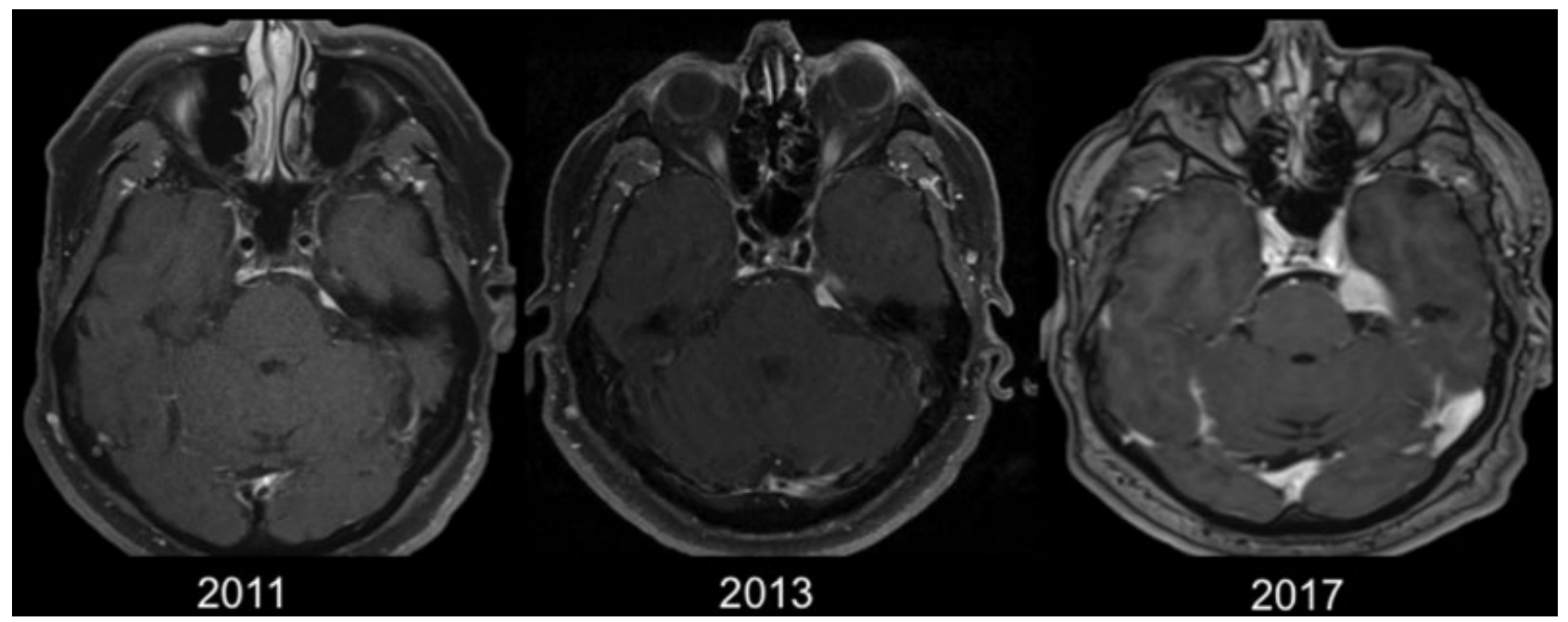

Fig. 1 T1-weighted axial MRI with gadolinium demonstrating progressive enlargement of a left petrous apex meningioma with extension into Meckel's cave. MRI, magnetic resonance imaging.

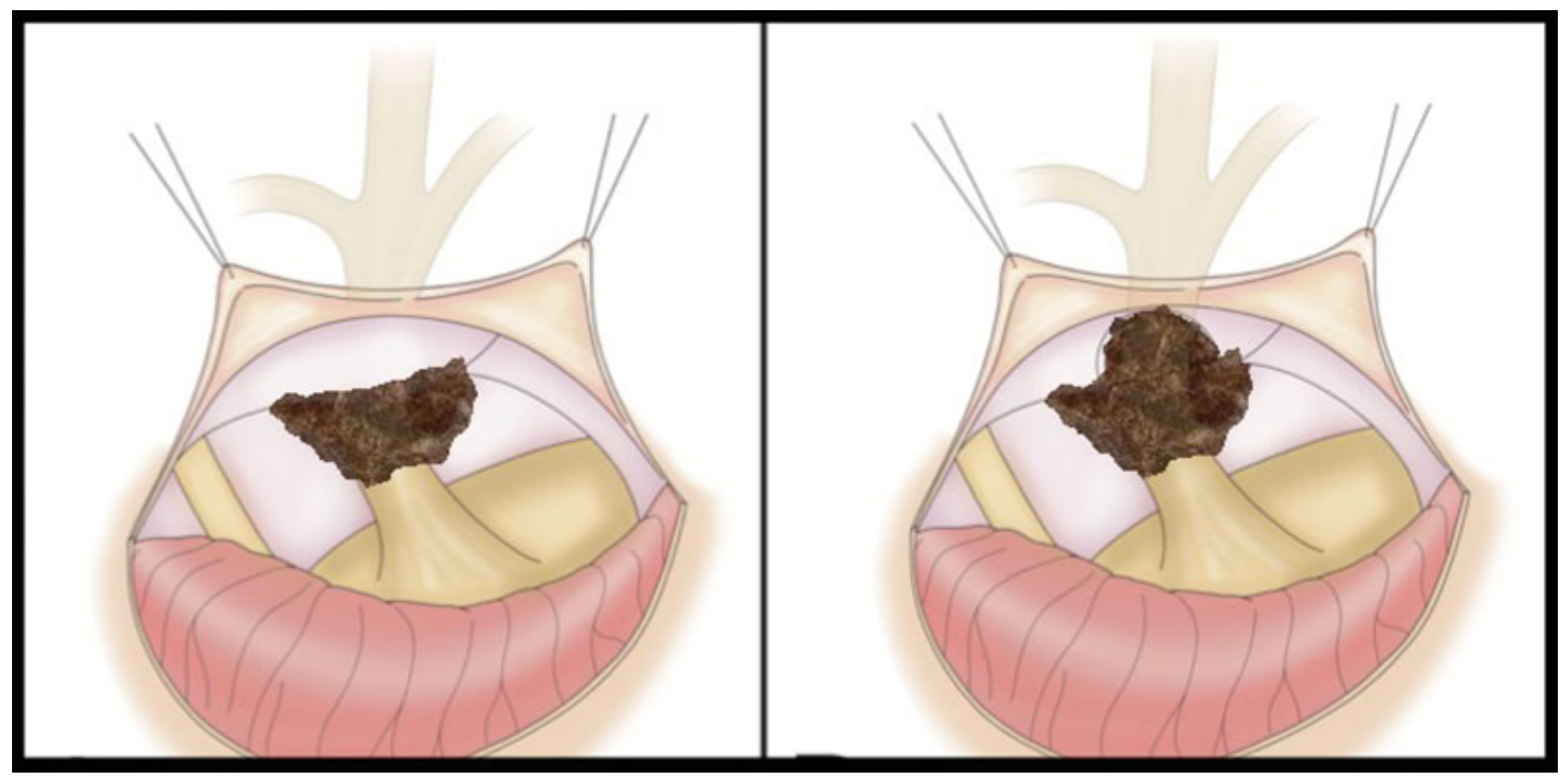

Fig. 2 Schematic demonstrating the access to Meckel's cave achieved after intradural suprameatal drilling.

\section{References}

1 Samii M, Tatagiba M, Carvalho GA. Retrosigmoid intradural suprameatal approach to Meckel's cave and the middle fossa: surgical technique and outcome. J Neurosurg 2000;92(02):235-241

2 Kawase T, Toya S, Shiobara R, Mine T. Transpetrosal approach for aneurysms of the lower basilar artery. J Neurosurg 1985;63(06): 857-861

3 Seoane E, Rhoton ALJr. Suprameatal extension of the retrosigmoid approach: microsurgical anatomy. Neurosurgery 1999;44(03): 553-560

4 Chanda A, Nanda A. Retrosigmoid intradural suprameatal approach: advantages and disadvantages from an anatomical perspective. Neurosurgery 2006;59(01, Suppl 1):ONS1-ONS6, discussion ONS1-ONS6 